\title{
Study of adherence and effect of iron and folic acid supplement on haemoglobin level among adolescent girls in rural area
}

\author{
Bina M. Kuril ${ }^{1}$, Chetan Janbade ${ }^{2}$, Deepak K. Lone ${ }^{3} *$, Salma Hirani ${ }^{1}$, Ankushe R. T. ${ }^{1}$, \\ Mohan K. Doibale ${ }^{1}$
}

\footnotetext{
${ }^{1}$ Department of Community Medicine, Govt. Medical College, Aurangabad, Maharashtra, India

${ }^{2}$ Shri Vasantrao Naik, Government Medical College, Yeotmal, Maharashtra, India

${ }^{3}$ Health Services, Leprosy, Jalna, Maharashtra, India
}

Received: 05 February 2016

Accepted: 05 March 2016

\author{
*Correspondence: \\ Dr. Deepak K. Lone \\ E-mail: dpklone@gmail.com
}

Copyright: (C) the author(s), publisher and licensee Medip Academy. This is an open-access article distributed under the terms of the Creative Commons Attribution Non-Commercial License, which permits unrestricted non-commercial use, distribution, and reproduction in any medium, provided the original work is properly cited.

\begin{abstract}
Background: The NFHS-3 data suggests that anaemia among adolescent Indian girls (15-19 years) is 56\%. The control of anaemia in adolescent girls can be more easily achieved if a satisfactory iron status can be ensured in this important phase of life. This study estimated the prevalence of anaemia among adolescent girls, their adherence and compliance to IFA and studied effect of IFA supplementation on haemoglobin level of adolescent girls.

Methods: Community based cross-sectional study was carried out among 378 adolescent girls during June 2012 to May 2013 by house to house survey. All the relevant information was collected in predesigned proforma. The clinical examination, anthropometric examination and by Sahli's haemoglobin meter, estimation of haemoglobin were done. Participants were given iron and folic supplementation for 45 days at the time of home visit and subsequently for another 45 days. Adherence to IFA was assessed through pill count.

Results: Prevalence of anaemia in the adolescent girls was found to be $68.5 \%$. Majority of girls were having mild anaemia. Before intervention the mean haemoglobin was $10.61 \pm 1.32$ and after intervention it was $11.02 \pm 1.06$ $(\mathrm{p}=0.001)$. Adherence to treatment was found in $85.19 \%$ of study participants.

Conclusion: Prevalence of anaemia among adolescent females was high in rural study area. The declining trend was observed in grades of anaemia, there was conversion of moderate anaemia to mild anaemia and non-anaemia which was significant. The mean haemoglobin levels were increased after supplementation of IFA in study participants.
\end{abstract}

Keywords: Adolescent girls, Anaemia, IFA supplementation

\section{INTRODUCTION}

In India the proportion of population with anaemia is $74.3 \%$. India is home to nearly 113 million adolescent girls between the ages of 11 and 18 years, and $90 \%$ of them (i.e. 104 million girls) live in the 15 largest states of the country. The National Family Health Survey-3 (NFHS-3) data suggests that anaemia among adolescent girls (15-19 years) is 56 percent. ${ }^{1}$ A multi-centric study by the Indian Council of Medical Research showed that over $90 \%$ of adolescent girls throughout the country had some kind of anaemia. These findings were corroborated by a district level household survey in 2002-2004 showing that only $5 \%$ of adolescent girls did not have any kind of anaemia and a large proportion were suffering from severe anaemia. ${ }^{2}$ Anaemia is a major health problem in Maharashtra, India especially among women and children. About half (48\%) of women in Maharashtra are anaemic, including 33 percent with mild anaemia, 14 percent with moderate anaemia, and 2 percent with severe anaemia. $^{3}$ The present study was undertaken to assess the prevalence of anaemia among adolescent girls and to study the adherence \& the effect of iron and folic acid 
supplements on haemoglobin level among adolescent girls who belonged to the rural communities.

Objectives of the studies were; (1) to estimate the prevalence of anaemia among adolescent girls and to study the adherence and compliance to IFA supplementation among adolescent girls; (2) to study the effect of iron and folic acid supplementation on haemoglobin level of adolescent girls.

\section{METHODS}

Community based interventional study was carried out at field practice area of Rural Health and Training Centre, Paithan, Aurangabad, India to estimate the prevalence of anaemia and to study the adherence and the effect of IFA supplement on $\mathrm{Hb}$ level among adolescent girls during June 2012 to May 2013.

\section{Sample size}

The National Family Health Survey-3 (NFHS-3) data suggests that anaemia among adolescent girls (15-19 years) is 56 percent. $^{1}$

Sample size (n) was calculated with the help of formula as below. ${ }^{4}$

$$
\mathrm{n}=P \times(100-\mathrm{P}) \times \frac{z^{2}}{\varepsilon^{2}}
$$

Where, $\mathrm{P}$ is anticipated population proportion $=56 \%$, relative precision $(\varepsilon)=5.6 \%$, confidence level $=95 \%$ and $\mathrm{Z}$ is confidence coefficient $=1.96$. Thus the sample size derived was 378; so it was decided to cover the adolescent girls of ages 10-19 years as per the calculated sample size.

\section{Ethical consideration}

The ethical approval was obtained from the institutional ethical committee of Government Medical College Aurangabad, India. Co-operation and informed consent was taken from authorities and respondents of the concerned area.

\section{Inclusion criteria}

- Girls willing to participate in the study.

- Girls residing in the study area

\section{Exclusion criteria}

- Any active disease (acute or chronic) that could affect iron metabolism or cause anaemia through mechanisms other than nutritional deficiency.

- Recent hospitalization in past 6 weeks.

- Girls with history of regular Iron and folic acid supplementation for more than 1 month.
- Any patient with a documented history of gastrointestinal bleeding or perforation of ulcer in last 6 months.

- Previous history of hypersensitivity to Iron supplementations.

- History of blood loss due to accidents.

This study was conducted during June 2012 to May 2013 by house to house survey. After explaining the purpose and nature of study to the head of family and adolescents and thereafter seeking the permission from head of the family, girls were interviewed, clinical examination and anthropometric measurement recorded and estimation of haemoglobin level was done by Sahli's method. All girls were clinically examined for signs of anaemia, general and systemic examination was done in presence of female member of house.

The clinical examination, anthropometric examination and estimation of haemoglobin were done by investigator himself. Haemoglobin was estimated by Sahli's haemoglobin meter.

Information regarding population of study area was collected form national informatics centre. Estimated population of the studied area was 34,000 during 20122013. According to UNICEF 2011, population of adolescent girls was $(11.23 \%) .^{5}$ On the basis of this information, investigator selected every 10th house to cover the entire population for achieving desired sample size of 378 . If study subject not found at $10^{\text {th }}$ house, immediate next house was considered till the desired subject obtained.

\section{Stages of intervention}

\section{Stage 1 pre-intervention}

House to house survey was carried out to enrolled 378 subjects in the study. Adolescents were interviewed, clinical examination was carried out, anthropometric measurements were recorded by standard procedures and haemoglobin estimation was done before intervention.

\section{Stage 2 Intervention}

Participants were given iron and folic supplementation for45 days at the time of home visit. Subsequently visit was given to participants to replenish another next dose of iron and folic acid supplementation for 45days.Adherence to iron and folic acid supplement was assessed through pill count.

\section{Stage 3 post-intervention}

After completion of treatment, participants were asked to come at RHTC for haemoglobin estimation. Post intervention assessment was done to know haemoglobin status of participants after intervention with iron and folic acid supplementation and to know the adequacy of 
treatment, if not reasons for non-compliance was ascertained.

\section{Adherence assessment}

Pill count adherence

Adherence was checked by counting empty blisters of supplementation. Participants defined as adherent if they consumed $75 \%$ or more of the prescribed supplementation, which translates of taking tablets at least 5 days/week were considered adherent.

\section{RESULTS}

It was found that $259(68.5 \%)$ girls were anaemic and $119(31.5 \%)$ girls were non-anaemic. Prevalence of anaemia in the adolescent girls was found to be $68.5 \%$. About severity of anaemia in girls, out of total 378 adolescent girls, 148 were in category of mild anaemia, followed by 108 girls with moderate anaemia and 3 were having severe anaemia. In the present study it was observed that most of the girls i.e. 148 (39.2\%) were suffering from mild anaemia (Table 1).

Table 1: Prevalence and grades of anaemia in adolescent girls.

\begin{tabular}{|lll|}
\hline Anaemia Status & Number & Percentage \\
\hline Non anaemic & 119 & $31.5 \%$ \\
\hline Anaemic & 259 & $68.5 \%$ \\
\hline Mild anaemia & 148 & $39.2 \%$ \\
\hline Moderate anaemia & 108 & $28.6 \%$ \\
\hline Severe anaemia & 3 & $0.8 \%$ \\
\hline Total & 378 & $100 \%$ \\
\hline
\end{tabular}

The mean haemoglobin values before and after intervention with iron and folic acid supplementation. Before intervention the mean haemoglobin was $10.61 \pm 1.32$ and after intervention $11.02 \pm 1.06(\mathrm{p}=0.001)$ (Table 2).

\section{Table 2: Mean haemoglobin ( $\mathrm{Hb})$ of adolescent girls} before and after intervention.

\begin{tabular}{|lrl|}
\hline Haemoglobin status $(\mathrm{g} \%)$ & Mean \pm S.D & P value \\
\cline { 1 - 2 } Before intervention & $10.61 \pm 1.32$ & $\mathrm{p}=0.001$ \\
\cline { 1 - 2 } After intervention & $11.02 \pm 1.06$ & \\
\hline
\end{tabular}

At the baseline, 119 (31.5\%) were non anaemic and 259 $(68.5 \%)$ were anaemic. A declining trend was observed after intervention i.e. $94(38.68 \%)$ were non anaemic and $149(61.32 \%)$ were anaemic (Table 3$)$.

At the baseline mild anaemic were 148 (39.2\%) and moderate anaemic were $108 \quad(28.6 \%)$ and after intervention, mild anaemic were 117 (48.15\%) and moderate anaemic were $32(13.17 \%)$ respectively (Table 4).
Table 3: Distribution of anaemia before and after intervention.

\begin{tabular}{|lcc|c|}
\hline Anaemia & $\begin{array}{c}\text { Non- } \\
\text { Anaemic }\end{array}$ & Anaemic & Total \\
\hline $\begin{array}{l}\text { Pre- } \\
\text { intervention }\end{array}$ & $\begin{array}{c}119 \\
(31.5 \%)\end{array}$ & $\begin{array}{c}259 \\
(68.5 \%)\end{array}$ & $\begin{array}{c}378 \\
(100 \%)\end{array}$ \\
\hline $\begin{array}{l}\text { Post- } \\
\text { intervention }\end{array}$ & $\begin{array}{c}94 \\
(38.68 \%)\end{array}$ & $\begin{array}{c}149 \\
(61.32 \%)\end{array}$ & $\begin{array}{c}243 \\
(100 \%)\end{array}$ \\
\hline
\end{tabular}

$\{\mathrm{p}=0.001$ (McNemar test) $\}$

Table 4: Distribution of anaemia in girls according to severity in pre and post -intervention group.

\begin{tabular}{|c|c|c|}
\hline $\begin{array}{l}\text { Grades of } \\
\text { anaemia }\end{array}$ & $\begin{array}{l}\text { Pre-intervention } \\
\text { group }\end{array}$ & $\begin{array}{l}\text { Post- intervention } \\
\text { group }\end{array}$ \\
\hline & Number (\%) & Number $(\%)$ \\
\hline Mild anaemic & $148(39.2)$ & $117(48.15)$ \\
\hline $\begin{array}{l}\text { Moderate } \\
\text { anaemic }\end{array}$ & $108(28.6)$ & $32(13.17)$ \\
\hline Total & $256(100)$ & $149(100)$ \\
\hline
\end{tabular}

$\mathrm{p}=0.001$ (McNemar test).

The decline of moderate anaemia was observed due to conversion of moderate anaemic to mild anaemic and to non-anaemic (Figure 1).

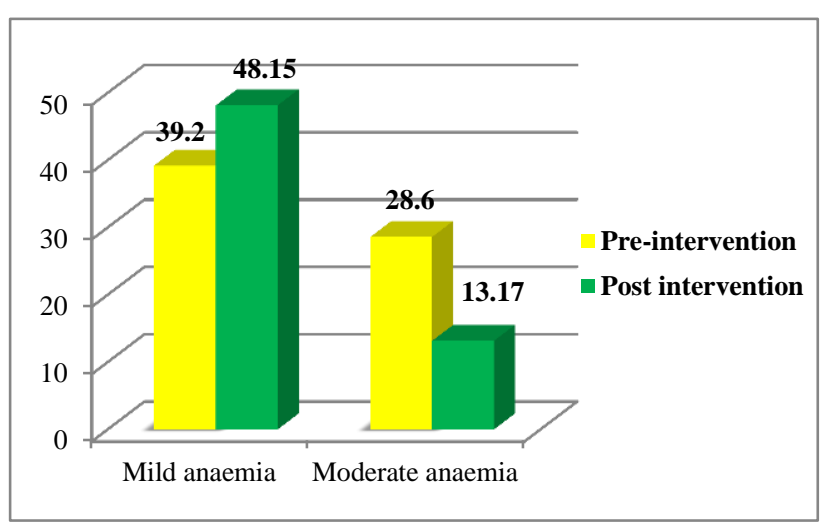

Figure 1: Grades of anaemia in girls in Pre and Post intervention group

Total 135 study participants out of 378 were drop-outs from the study. At stage II -Intervention, 36 were not found at their homes and at stage III-Post intervention another 99 were drop outs (Table 5).

Table 5: Drop out participants during follow up study at various stages

\begin{tabular}{|lcc|}
\hline Stages & $\begin{array}{l}\text { No. of } \\
\text { participants }\end{array}$ & Drop out \\
\hline Stage I- pre-intervention & 378 & 0 \\
\hline Stage II - intervention & 342 & 36 \\
\hline Stage III- post intervention & 243 & 99 \\
\hline Total drop outs & & 135 \\
\hline
\end{tabular}


Table 6: Adequacy of treatment in adolescents.

\begin{tabular}{|lcc|}
\hline IFA tablet consumed & Number & Percentages \\
\hline Adequate $(>75 \%)$ & 207 & 85.19 \\
\hline Inadequate $(<75 \%)$ & 36 & 14.81 \\
\hline Total & 243 & 100 \\
\hline
\end{tabular}

Total 243 participants visited to RHTC for haemoglobin estimation. Out of them 207 participants had consumed $>75 \%$ of supplements and 36 consumed $<75 \%$ (Table 6 ).

Significant association with age category, parent's education, socioeconomic status and BMI was found in participants with adequate treatment (Table 7).

Table 7: Distribution of variables of participants with adequate treatment.

\begin{tabular}{|c|c|c|c|c|}
\hline \multirow[t]{2}{*}{ Variable } & & \multicolumn{2}{|c|}{ Adequate $(>75 \%) n=207$} & \multirow[t]{2}{*}{ P value } \\
\hline & & Non anaemic & Anaemic & \\
\hline \multirow[t]{2}{*}{ Age category } & Early adolescent & 68 & 77 & \multirow[t]{2}{*}{0.005} \\
\hline & Late adolescent & 16 & 46 & \\
\hline \multirow[t]{2}{*}{ Father's education } & $<$ Middle school & 29 & 72 & \multirow[t]{2}{*}{0.001} \\
\hline & > Middle school & 55 & 51 & \\
\hline \multirow[t]{2}{*}{ Mother's education } & $<$ Middle school & 42 & 88 & \multirow[t]{2}{*}{0.002} \\
\hline & > Middle school & 42 & 35 & \\
\hline \multirow[t]{2}{*}{ Socioeconomic status } & $\geq$ Upper middle & 28 & 13 & \multirow[t]{2}{*}{0.001} \\
\hline & $<$ Upper middle & 56 & 110 & \\
\hline \multirow[t]{2}{*}{ Diet Nature } & Vegetarian & 34 & 68 & \multirow[t]{2}{*}{0.047} \\
\hline & Mixed & 50 & 55 & \\
\hline \multirow[t]{2}{*}{ BMI } & $<18.50$ & 21 & 90 & \multirow[t]{2}{*}{0.001} \\
\hline & $>18.50$ & 63 & 33 & \\
\hline
\end{tabular}

\section{DISCUSSION}

Prevalence of anaemia among adolescent girls was found to be $68.5 \%$. Similar results were documented previously by Kaur $\mathrm{S}$ et al with $59.8 \% .^{6}$ Prevalence of anaemia Sharda S, Kanta K reported $70.50 \%$ girls with anaemia. Baral KP, Onta SR reported $78.3 \%$ prevalence of iron deficiency anaemia among adolescent girls. ${ }^{7,8}$ Our results are also consistent with Dutt R, Patils et al (61\%), Chandra Sekhar et al $(68.95 \%)$ and Jayasree $\mathrm{P}$, Sushamabai S et al. ${ }^{9-11}$ While some authors have reported low prevalence of anaemia among adolescent girls like Basu S, Hazarika R et al who reported $23.9 \%$ prevalence of anaemia among adolescent girls. ${ }^{12}$ Goel S, Gupta B found that $13.3 \%$ girls were anaemic while Chaudhary $\mathrm{SM}$ et $\mathrm{al}^{14}$ found $35.1 \%$ subjects were anaemic. ${ }^{13,14}$ In our study we found that out of 378 adolescent girls, 148 $(39.2 \%)$ were in category of mild anaemia, followed by moderate anaemia $108(28.6 \%)$ and severe anaemia 3 $(0.8 \%)$ (Table 1$)$. Our findings are consistent with the studies done by Rajaratnam J et al, Sharda $\mathrm{S}$ et al, Goyle A, Prakash S and Chaudhary SM et al. ${ }^{7,13}$ Gupta A, Paraskar A et al conducted study in1596 adolescent girls of age (10-19 years). ${ }^{16}$ It was seen that among the anaemic adolescent girls, $77.3 \%$ had mild anaemia, $21.9 \%$ had moderate anaemia, and $0.9 \%$ had severe anaemia. Present study differs from the study done by Rawat CMS et al who reported $19.0 \%$ mild, $14.1 \%$ moderate and $1.4 \%$ severe anaemia in adolescent girls. ${ }^{17}$
The mean haemoglobin before intervention and after intervention was $10.61 \pm 1.32$ and $11.02 \pm 1.06$ respectively (Table 2). It was observed that haemoglobin levels were increased after intervention in participants and it was statistically significant $(\mathrm{p}=0.001)$.

Joshi M, Gumashta $\mathrm{R}$ in their study found that the mean pre intervention haemoglobin was $10.1 \pm 1.1 \mathrm{gm} / \mathrm{dl}$ and mean rise in haemoglobin after 3 month was $11.2 \pm 1.0$ $\mathrm{gm} / \mathrm{dl}^{18}$ The increase in $\mathrm{Hb}$ percentage was statistically significant. Aggarwal KN reported that the initial baseline mean haemoglobin in daily treatment group was $11.7 \pm 1.3$ and after interventions with iron and folic acid supplementation mean haemoglobin level was $12.3 \pm 1.1$. $^{19}$ A daily treatment group showed the maximum rise. So our findings are consistent with these studies.

In our study, at baseline, $119(31.5 \%)$ girls were non anaemic and 159 (68.5\%) were anaemic. A declining trend was observed after intervention i.e. 94 (38.68\%) were non anaemic and $149(61.32 \%)$ were anaemic. This difference was found to be statistically significant with $\mathrm{p}=0.001$ (Table 3).

At the baseline mild anaemic girls were $108(28.6 \%)$ and moderate anaemic girls were $148(39.2 \%)$ and after intervention mild anaemic were 117 (48.15\%) and moderate anaemic were $32(13.17 \%)$. Thus the declining trend was observed in grades of anaemia, There was 
conversion of moderate anaemia to mild anaemia and to non-anaemia which was significant with $\mathrm{p}=0.001$ (Table 4).

Joshi M, Gumashta $\mathrm{R}$ found that the prevalence of anaemia among daily treatment group was $100 \%$ which was brought down by $25 \%$ in iron folic acid supplementation' group after the IFA supplementation and it was statistically significant $(\mathrm{p}=0.001) .{ }^{18}$ Also the pre-intervention mild and moderate anaemia was $61.67 \%$ and $36.67 \%$ respectively. After intervention mild and moderate anaemia was $65 \%$ and $10 \%$ respectively. There was decline of moderate anaemia to mild anaemia $(\mathrm{p}=0.001)$.

Deshmukh, PR et al reported that at the baseline 226 $(62.8 \%)$ study participants were anaemic and after intervention it remains $155(51.6 \%){ }^{20}$ This decline was statistically significant among rural girls $(\mathrm{p}=0.001)$. The baseline mild anaemic participants were 165 (46.0\%) and moderate anaemic were $53(14.8 \%)$ and after intervention their number were $110(37.2 \%)$ and 44 (14.9\%) respectively which was statistically significant $(\mathrm{p}=0.001)$. These two studies confirm our results.

Among 378 study participants, 36 were drop outs at the stage II of intervention and among remaining 99 were drop outs at the post intervention (stage III) level (Table 5). Reasons for dropout were as follows;

- Nobody was accompanied to bring the girls to RHTC for $\mathrm{Hb}$ estimation due to working parents.

- Because of household work.

- Girls were supposed to work at home and do not allow to go out.

Out of total 243 participants visited to RHTC for haemoglobin estimation, $207(85.19 \%)$ consumed $>75 \%$ supplementation and $36(14.81 \%)$ consumed $<75 \%$ supplementation (Table 6). Reasons for non-adherence to treatment were;

- Poor compliance was due to forgetfulness to take tablets. Despite being aware of its health benefits, participants refrained from consuming iron folic acid tablets.

- The participants reported side effects to the tablets like nausea, vomiting, constipation, anxiety.

- Annoyance of frequency of tablets taken.

Some variables such as age category, parent's education, socioeconomic status and BMI were found to be significantly associated with with adequate treatment in study participants (Table 7).

\section{CONCLUSION}

The overall prevalence of anaemia among adolescent females was high in our rural study area (68.5\%). Majority of girls were having mild anaemia. The mean haemoglobin levels were increased after supplementation of IFA tablets in study participants. The declining trend was observed in grades of anaemia, there was conversion of moderate anaemia to mild anaemia and non-anaemia which was significant. Adherence to treatment was found in $85.19 \%$ of study participants.

\section{Recommendation}

- These results warrant a need for a special attention to anaemia among adolescent age group, and eventually encourage the development of directed educational and nutritional programs to safeguard the well-being of these future mothers.

- Periodic surveys should be done in community on anaemia for updating prevalence.

- Enhancement of educational status of parent's is imperative to reduce the adherence to medication.

- For improvement the proportion of compliance to medication further close supervision is recommended.

- Regular supply of iron and folic acid supplementation is requisite to schools.

The limitations of the study were it was conducted in rural area which is a field practice area of our College. This area may not be representative for the other rural areas of Maharashtra, India.

\section{Funding: No funding sources}

Conflict of interest: None declared

Ethical approval: the ethical approval was obtained from the institutional ethical committee of government medical college Aurangabad, Maharashtra, India

\section{REFERENCES}

1. Gupta, Anuradha MS, Kumar R, Salhotra VS, Mohan A DSR. Guidelines for Control of Iron Deficiency Anaemia. New Delhi. 2013;54.

2. Agarwal KN, Agarwal DK, Sharma A, Sharma K, Prasad K, Kalita MC et al. Prevalence of anaemia in pregnant \& lactating women in India. Indian $\mathrm{J}$ Med. Res. 2006;124(2):173-84.

3. The FC, Mumbai W. CHAPTER 7. In: Kulkarni S, Mishra V,Parasuraman S, Mulay S, Talwalkar M, Chitanand R, editors. Natl. Fam.Heal. Surv.INDIA 1998n99 Maharashtra. Calverton, Maryland, USA. 2002;24.

4. Lwanga SK LS. Sample size determination in health studies. Lwanga SK, Lemshaw S. 1991;30.

5. The Adolescent Girls Anaemia Control Programme New Delhi. 2011; Available from: http://www.unicef.org/india/14._Adolescent_Anaemi a_Control_Programme.pdf Accessed 12 Jan 2016.

6. Kaur S, Deshmukh PR, Garg BS. Epidemiological Correlates of Nutritional Anemia in adolescent girls of Rural Wardha. Indian J of Community Medicine. 2006;31(4):255-7. 
7. Sharda S, Kanta K, Uppal M. Prevalence of anaemia among adolescent girls of scheduled caste community of Punjab. Anthropologist. 2005;7(4), 265-7.

8. Baral KP, Onta SR. Prevalence of anemia amongst adolescents in Nepal, a community based study in rural and urban areas of Morang District. Nepal Med. Coll J. 2009;11(3):179-82. Available from:http://www.ncbi.nlm.nih.gov/pubmed/2033406 5.Assessed 12 Jan 2016.

9. Dutt R, Patil S, Joshi S, Mhatre R. Prevalence of anaemia among adolescent girls in rural area of Raigaddistrict, Maharashtra. 2009;40(3):3-6.

10. Chandra Sekhar K, Jyothi VN, Kumar KJK, Kumar DSS, Krishna CB, Tondare D. Prevalence of anaemia among adolescent girls in urban areas of Kadapa, A.P. Indian J Public Heal Res Dev. 2011;2(1).

11. Jayasree P, Sushamabai AS, Mathew A, Kadam RM, Varghese BA. Epidemiological factors affecting anaemia prevalence in rural adolescents in South India. Pushpagiri Med J. 2012;(3)4.

12. Basu S, Hazarika R. and Parmar V., Prevalence of anaemia among school going adolescents of Chandigarh. Indian Paediatr. 2005;597(42):17.

13. Goel S, Gupta B. Low anemia prevalence among adolescents of an urban hilly community. Indian J. Community Med. Medknow Publications and Media Pvt. Ltd. 2007 Jan 1;32(1):67.

14. Chaudhary SM, Dhage VR. A study of anemia among adolescent females in the urban area of
Nagpur. Indian J. Community Med. 2008 Oct;33(4):243-5

15. Rajaratham J, Rajaratham A. et al. Prevalence of anaemia among girls of Tamil Nadu. Indian Paediatrics. 2000;37:532-6.

16. Gupta A, Parashar A, Thakur A, Sharma D. Anemia among adolescent girls in Shimla hills of north India: Does BMI and onset of menarche have a role? Indian J Med Sci. 2012;66:126-30.

17. Rawat CMS, Garg SK, Singh JV. Socio demographic correlates of anaemia among adolescent girls in rural area of Meerut. IJCM. 2001;26(4):173-5.

18. Joshi M, Gumashta R. Weekly Iron Folate Supplementation in Adolescent Girls-An Effective Nutritional Measure for the Management of Iron Deficiency Anaemia. 2013;5(3):188-94.

19. Aggarwal, KN. Assessment of prevalence of anaemia and iron in response to daily/weakly iron folate supplement in adolescent girls (10-18) from urban slums of North Delhi. UNICEF Contract No. 95/0075/1998; $1-9$

20. Deshmukh, Garg PR, Bharambe MS. Effectiveness of Weekly Supplementation of Iron to Control Anaemia among Adolescent Girls of Nashik, Maharashtra, India. J Health Popul Nutr. 2008;26(1):74-8.

Cite this article as: Kuril BM, Janbade C, Lone DK, Hirani S, Ankushe RT, Doibale MK. Study of adherence and effect of iron and folic acid supplement on haemoglobin level among adolescent girls in rural area. Int $\mathbf{J}$ Community Med Public Health 2016;3:906-11. 